\title{
Quench Propagation and Protection Analysis of the ATLAS Toroids
}

\author{
A.Y. Dudarev', A.V. Gavrilin ${ }^{1}$, H.H.J. ten Kate ${ }^{1}$, D. E. Bnynham ${ }^{2}$, M. J. D. Courthold ${ }^{2}$ and C. Lesmond ${ }^{3}$ \\ 'CERN, ATLAS Mignet Project, EP Division, Geneva 23, CH-1211, Swilzerland \\ ${ }^{2}$ Rutherford Appleton Laboratory, UK, ${ }^{3}$ CEA/Saclay, France
}

\begin{abstract}
The ATLAS superconducting magnet system consists of the Bartel Toroid, two Fnd-Cap Toroids and the Central Solenoid. However, the Toroids of eight coils each are magnetically separate systems to the Central Solenoid. 'The 'Toroids are electrically connected in series and energized by a single power supply. The quench protection system is based on the use of relatively small external dump resistances in combination with quencl-heaters activated after a quench event detection to initiate the internal dump of stored energy in all the coils. $A$ rather strong quench-back effect due to eddycurrents in the coil casings at the transport current decay is beneficial for the quench protection efficiency in the event of heater failures. The quench behaviour of the $\boldsymbol{A T L} \boldsymbol{\Lambda} S$ Toroids was computer simulated for normal operation of the quench protection system and its complete non-operation (failure) mode.
\end{abstract}

\section{INTRODUCTION}

The magnet systcm of the ATLAS Toroids consists of the Batrel Toroid (BT) and two End-Cap Toroids (FCls) with overall dimensions of $20 \mathrm{~m}$ diameter and $25 \mathrm{~m}$ lenglh. The stored encrgy of the system is about $1.4 \mathrm{GJ}$ at the rated currenl of $20 \mathrm{kA}$, sec Table I, [1]. Each Toroid consists of 8 coils, and each coil of rectangular shape includes two double pancakes cmbedded in a massive aluminium-alloy casing (RRR $=2$ ), see Fig. 1. The pancake windings are wound with a Rutherford type $C$ a/NbTi composite superconducior strongly stabilized with pure aluminium in a rectangular shape. The conductors for the BT' and EC'I' are slightly different in size and current carrying capacily [1], see Tab]c I. In spite of the lact that each Toroid has 8 coils, it will not be sectioned electrically, but all coils are connected in scrics. This avoids an uneven redistribution of the current between coils under

TABIE I

MAIN CHARACTERISTICS OF THE ATLAS TOROIDS

\begin{tabular}{|c|c|c|}
\hline Characteristic & $\mathrm{BT}$ & $\mathrm{ECT}$ \\
\hline Number of eoils & 8 & $2 \times 8$ \\
\hline Self-inductance & $5.14 \mathrm{H}$ & $2.06 \mathrm{II}$ \\
\hline Operating eurent & $20 \mathrm{kA}$ & $20 \mathrm{kA}$ \\
\hline Stored erergy & $1030 \mathrm{MJ}$ & $410 \mathrm{MJ}$ \\
\hline Run-up wollage & $16 \mathrm{~V}$ & $16 \mathrm{~V}$ \\
\hline Bushar + cutrent leads resistance & $210 \mu \Omega$ & $240 \mu \Omega$ \\
\hline Operating peak field & $3.9 \mathrm{~T}$ & $4.0 \mathrm{~T}$ \\
\hline Critical eurent @ $4.5 \mathrm{~K} \&$ peak field & $>55 \mathrm{kA}$ & $>64 \mathrm{kA}$ \\
\hline Cotnductor sizo & $57 \times 12 \mathrm{~mm}^{2}$ & $41 x: 2 \mathrm{~m} m^{2}$ \\
\hline Conductor length & $54 \mathrm{~km}$ & $26 \mathrm{~km}$ \\
\hline
\end{tabular}

Manuseript received September 26. 1999

A.V. Dudarev e-maił Alexcy.Dudarev@cen.ch

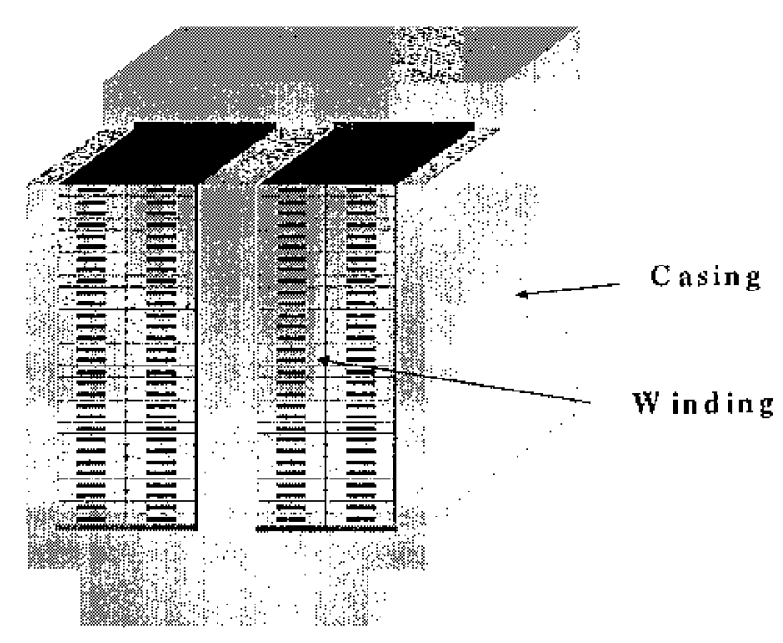

Tig. I Segment of the 13: coil. Full csoss-section of the winding bouth the double pincukes) in the casing. Visw on the tums.

quench and in doing so it excludes any mechanical overloads due to a disbalance of forces.

It is common knowledge that for such a large magnet syston, the hest way to dininish tho maximum temperature and internal voltage is to distribute the stored energy uniformly, because without that a fast discharge would requite a high clump resistance and hence high voltage in the circuit. The quench protection system of the ATI AS Toroids will use relatively small dump resistances and special quench-heaters enbedded in each double pancake of each coil [1]. The heaters will also guarante the magnel system discharging at low transport current during ramping.

Hore, the most simple electrical schemo is considered by which the Toroids and in fact all their coils are connected in series and energized by a single power supply. The mignet system quencl behaviour is computer simulated in the cases of complete non-operation of the quench protection system and when this system is triggered under normal operation.

\section{NORMAL ZONE PROPAGATION}

Special for a normal zone travelling in a compositc superconductor having a thick aluminium stabilizer is the rather slow electromagnetic diffusion process into the stabilizer $[2,3]$. The transport current ejected from the superconducting filaments into the copper matrix of strands can not penetrate at once into the full section of stabilizer. For example, the characteristic time scale of the current diffusion into the 


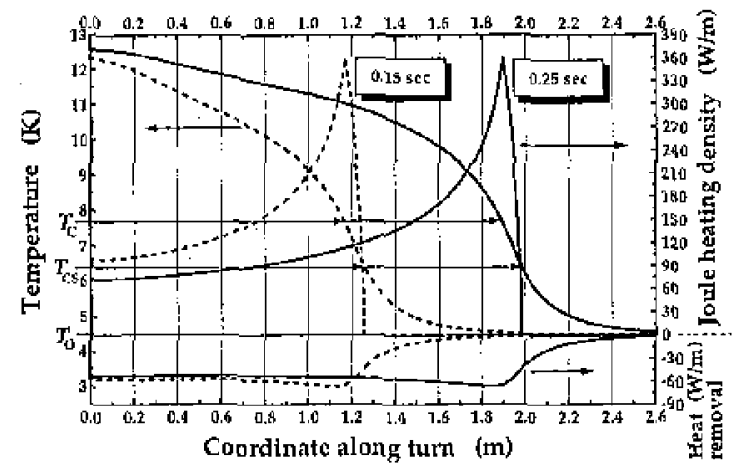

Fig. 2 Instant distributions of the temperature, Joule heating density and heat remowal epliciency along a turn of the BT coil wirkling. Fixed current $20.5 \mathrm{kA}$, magnetic lield $3.85 \mathrm{~T}$.

aluminium stabilizer of the BT conductor is about I $\mathrm{s}$, for the ECT conductor - somewhat loss. The dilference in specific stored energy in the cases where the transport current lows within the strands only and where it is uniformly distributed over lull cross-section of the conductor comes to a few tens of Joules per meter of conductor. This relalively high initial energy density is sulficient to transfer the conductor into the normal state and then to increase its temperature by several degrees. This energy transferted into Joule heating is nonunilormly distributed over lise cross-section of the conductor and this distribution varies with time. Consequently, the diffusion process has to be taken into account through a proper model. In our recent computations, a rather simple, but effective model as explained in work [3] was used. The computation results show that the lion's share of the "extra energy" is released just in the vicinity of the as-boundary, where the diffusion process is in the opening stage, as may be inferred from Fig. 2. This inevitably leads to a considerable increase of the normal zone velocity as opposed to the case where the characteristic time scale of the diffusion is assumed to come close to zero.

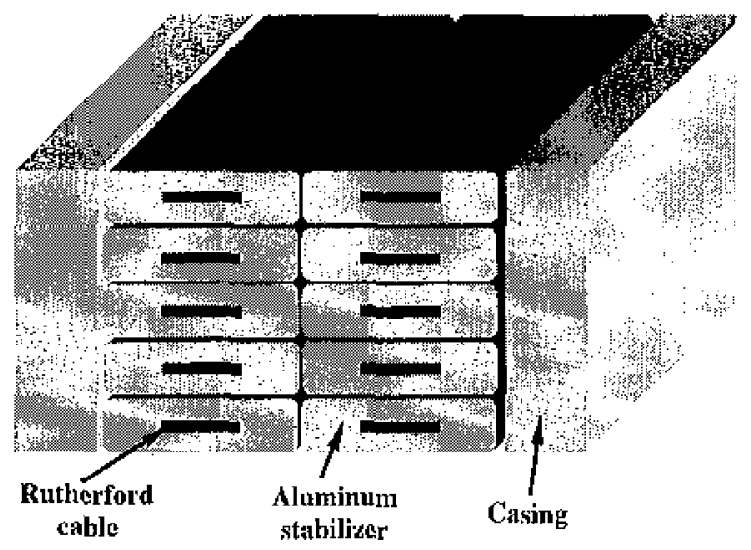

Fig. 3 Small section of the Toroid coil, the double pancake in the casing. Sketch.

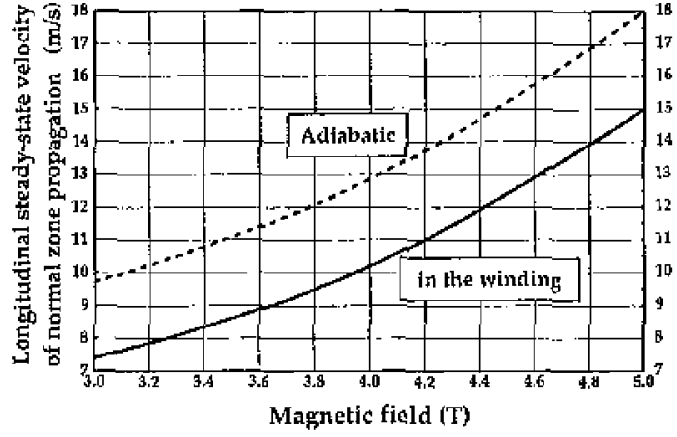

Fig. 4 Dependence of the propagation velocity along the ECT conductor on magnetic field at the rated current of $20 \mathrm{kA}$.

To determine the normal zone propagation velocity along the turns of the windings of the BT and ECT coils, a $3 \mathrm{D}$ model for the double pancake scction was used (Fig. 3). The transient transverse heal conduction through the insulation between the turns as well as between the turns and the casing, and also the electromagnetic diffusion process are correctly included. The 3D non-lincar transient heat problem is numerically solved using the finite difference method. This approach enaliled the curves given in Fig. 2 to be obtained as well as the results shown in Fig. 4. Referring to Fig. 4, the longitudinal propagation velocity in the ECT coil winding is roughly $30 \%$ lower than the adiabatic velocity due to the transicnt transwerse beat transfer (practically the same for the BT). Nevertheless, for the ECT, the steady-state velocity still is about $10 \mathrm{~m} / \mathrm{s}$ at the peak field of $4 \mathrm{~T}$ at $20 \mathrm{kA}$. T'bis inplies that the coil winding normalization tinse in the longitudinal direction is about $2-3 \mathrm{~s}$, only slightly influenced by the magnetic field distribution. In the BT coil winding, the longitudinal velocity approximates $7 \mathrm{~m} / \mathrm{s}$ at the peak field of $3.85 \mathrm{~T}$, and the longitudinal normalization time is close to 6-7 $\mathrm{s}$.

To determine the transverse propagation characteristics, a 2D model is used instead. The longitudinal heat conduction is neglected, because its influcnce on the transverse propagation velocity is assumed to be rather weak. This minot simplification cnables with the same computation capacity to consider the full cross-section of the coil winding (Fig. 1), and even cross-sections of several coils at onco.

The normalization time of the BT or ECT coil winding cross-sections depends on details of the normal zone initiation. According to the results oblained, in the worst case of a normal zone origination at one of the lowermost turns of anc double pancake, the transverse normalization time for the BT coil winding approximates $8 \mathrm{~s}$ at $3.85 \mathrm{~T}$ and $20 \mathrm{kA}$. However, when, as is planned, a $1 \mathrm{~mm}$ thick pure aluminium sleet on each of the four outside [aces of the double pancake between the casing and winding is used, this time could be decreased down to $6-6.5 \mathrm{~s}$. The transvetse normalization of the ECT coil winding takes abont $5 \mathrm{~s}$ at $4 \mathrm{~T} @ 20 \mathrm{kA}$. When the real field distribution is taken into account instead of a certain average field, the computed normalization times increase by 
$\sim 30 \%$. In the case of a simultancous normal zone initiation by the heaters in both the double pancakes, the transverse normalization time is almost halved.

Thus, it is concluded that the BT and ECT coil winding normalization is within the $10 \mathrm{~s}$ time frame which is an order of magnitude shorter than the easily estimated characteristic time of the cutrent decay in the whole magnet system under quench. It means that in the computer simulation of a quench event in this magnet systent, it is possible to consider cach coil in the 2D approximation correctly and to make rather solid estimates of the maximum temperature and internal voltage. In such a simulation, as performed, the heat equations are solved together will the circuit equations and include eddy current generation offect in the coil casings due to

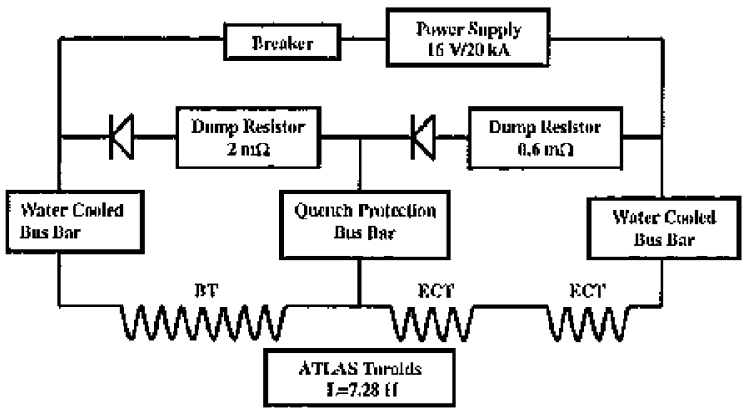

Fig. 5 The principle power circuit of the ATLAS Toroids magnet system ender normal operalion.

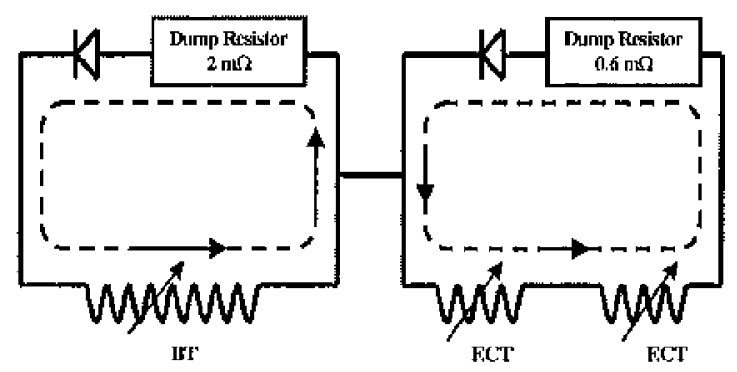

Fig. 6 Electrical scleme of the ATLAS Toroids in the fagt discharge jnode.

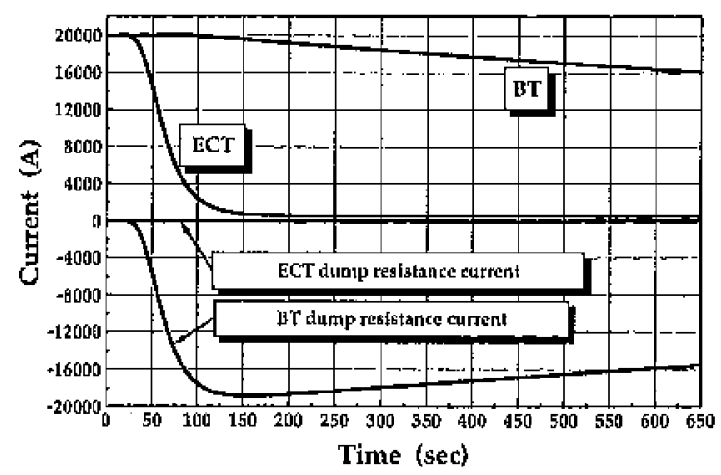

Fig. 7 Current decay in the ECTs and BT in the case of complete nonoperation of the quench protection systen; the ECTs under quench.

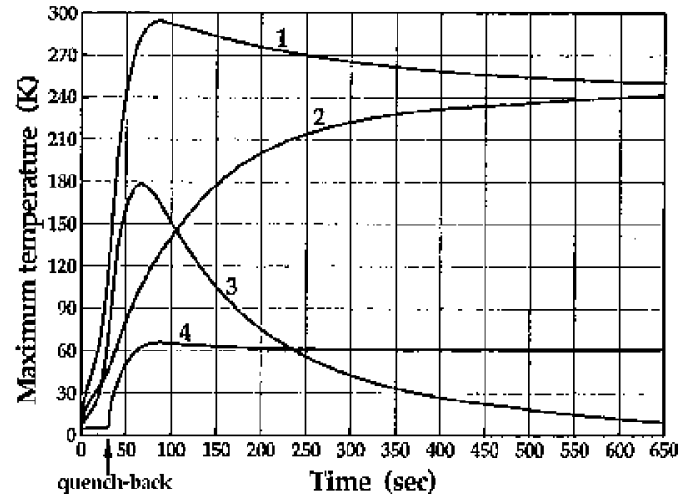

Fig. 8 Maxitnum temperatute in the ECT coils under quench in the ease of complete non-cperntion of the quench protection system. I - quenched coil winding,

2 - quenched coil onsing,

3-temperature gradient between the winding and easing of quenched coil,

4 -other 15 coil windings .

the transport current decay.

\section{QUENCH SIMULATION RESULTS}

The principle electrical circuit under study and corresponding to normal operation of the ATLAS Toroids is shown in Fig. 5. Quench event detection has to cause the heaters activation and a change-over from the nomal operation mode to the fast discharge mode (Fig. 6) as a result of a change of state of the breaker. In the fast discharge mode, there practicatly exist two circuits, the first one - for the BT, the socond - for the RCTs. These circuits are inductivoly coupled, but this coupling is very weak, as the mutual inductance belweon ECTs and BT is only $0.07 \mathrm{H}$, whereas the selfinductances of the BT and ECTs are $5.14 \mathrm{H}$ and $2.06 \mathrm{H}$, rospectively.

In the event of a quench, the two limiting cases are considered and simulated. The first case is the worst one where the quench detection and switch system unpredictably and completely fails and the magnet system remains in the normal operation mode with the power supply in service (the maxi-

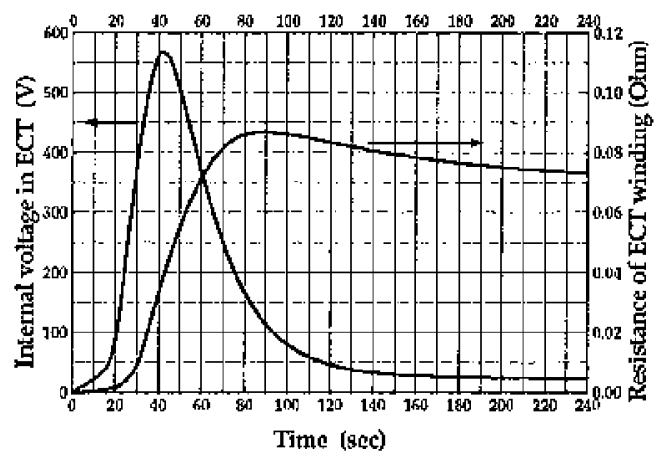

Fig. 9 Interthal voltage in the ECT and resistanes of the ECT winding in the case of eomplete non-operation of the quench protection systen. 


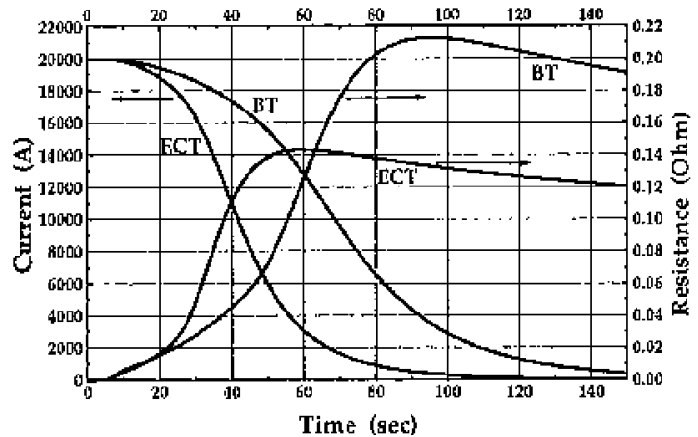

Fig. 10 Current decay and resistance of the windings of the BT and ECT's under nornal operation of the quench protection system.

mum voltage $16 \mathrm{~V}$ ), see Fig. 5 . In the second case, the magnet system successlully goes on to the fast discharging (Fig. 6) with $5 \mathrm{~s}$ delay. In both the cases a normal zone is initiated at one of the lowermost turns of one pancake in one coil of the ECT that is the most severe initial condition.

The computation results corresponding to the first case are given in Figs. 7-9. As illustrated, the current in the ECTs decays mainly because of a rather fast rise of the quenched coil resistance, while no current flows through the external dump resistunce of the ECTs due to the diode (Fig. 5). The current decay tads to a quench initiation in the other 15 coils of the BCTs due to eddy current generation in the casings (the quench-back) a lalf minute alter the quench has started in the first coil (Fig. 8). As a result, the ECTs discharge accelerates.

At the same time, the B'T coil windings remain superconducting, because the rising negative current through the BT dump resistance almost batances out the tansport current decay in the whole circuit, see Fig. 7 . A very slow discharge of the BT takes place with a rate being insufficiont to have the quench-back effect as in the ECTs.

Despite the fact that the BT coil windings are kept superconducting, the opposite could vastly accelerate the whole

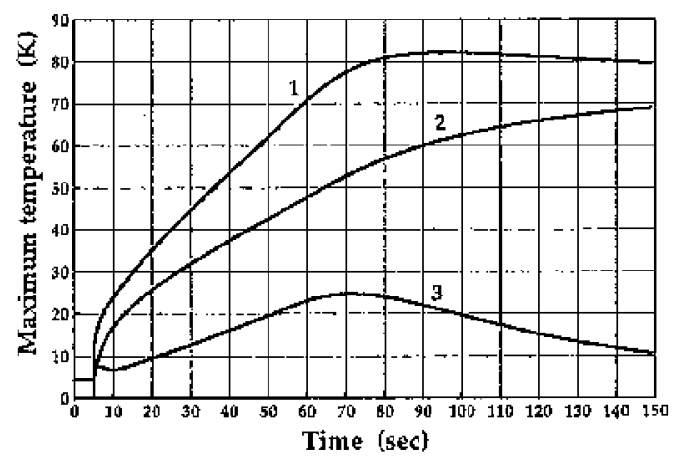

Fig. II Maximum temperatures in the BT under normal operation of the quench protection system.

$\mathrm{I}-\mathrm{BT}$ coil windings, $2-\mathrm{B}^{\prime} \mathrm{T}^{\mathrm{c}}$ coil casings,

3 - temperature gradient between the winding and casing.

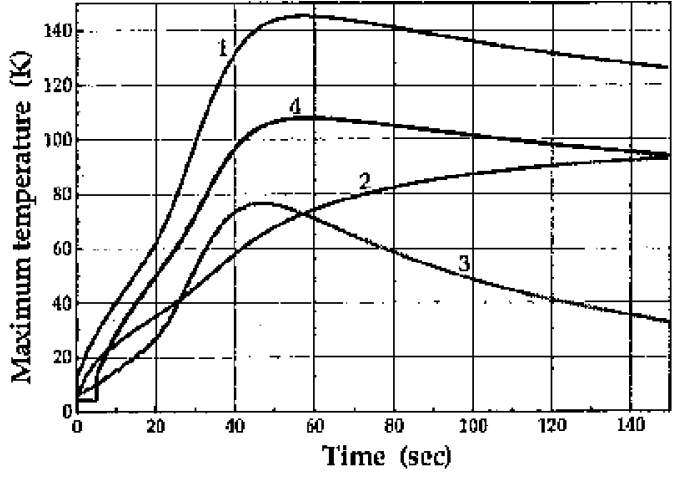

Fig. 12 Maxitmm temperntures in the ECT coils under normal opecation of the quench protection system.

1 - quenched coil windiug, 2 - quenched coil casing. 3 - temperature gradient belween the winding and casing, 4 - other 15 coll windings.

magnet system discharging and does nothing but inprove the siluation, the maximum temperalure of the quenched coil of the ECl turns out to be about only $300 \mathrm{~K}$, see Fig. 8. The maximum internal voltage does not exceed $600 \mathrm{~V}$, see Fig, 9.

The results corresponding to the case of normal operation of the guench protection system are shown in Figs. 10-12. In this case, the maximum temperatures of the BT and BCT windings are moderate, $\sim 85 \mathrm{~K}$ and $\sim 145 \mathrm{~K}$, respectively. The naximum internal voltages in the BT and ECT are negligible.

\section{CONCLUSIONS}

The quench behaviour of the $\Lambda \mathrm{TL} \Lambda \mathrm{S}$ Toroids magnet system energized by a single power supply was numortcally analyzed in the case of complete non-operation of the quench protection systen and in notmal operation of this system. In the first case, the magnet system proved itsolf as a selfprotected one, no over-heating nor over-voltage. Further, it is shown that normal operation of the quench protection system reduces the maximum temperature of the Toroids coils at least by half and minimizes the internal voltnges.

\section{REFEIENCES}

[I] Ter Kate $H$ "The Superconducting Magnet System for the ATLAS Detector" This Conjerence 1999

[2] Huang X Eyssi $Y$ Hilit M Adv. Covog, Fng 199353 IS5-163

[3] Gavrilin A Yanagi N Satoh S Motojima O Adv. In Superconductivity XI (Mroc of ISS'g8, November, I9P8, Fukuoka) 19992 1447-1450 